\title{
Mapping of Aluminous Rich Laterite Depositions through Hyper Spectral Remote Sensing
}

\author{
M. J. Ratnakanth Babu1, E. N. Dhanamjaya Rao², Lalitha Kallempudi'3, Das Iswar Chandra4 \\ ${ }^{1}$ Department of Mines \& Geology, Government of Andhra Pradesh, Vijayawada, India \\ ${ }^{2}$ Department of Geology, Andhra University, Visakhapatnam, India \\ ${ }^{3}$ Department of Geography, Andhra University, Visakhapatnam, India \\ ${ }^{4}$ National Remote Sensing Centre, Hyderabad, India \\ Email:ratnakanth@yahoo.com,dhananjaya_e@yahoo.com, lalitha_1321@yahoo.com, icdasiirs@gmail.com
}

How to cite this paper: Babu, M.J.R., Rao, E.N.D., Kallempudi, L. and Chandra, D.I. (2018) Mapping of Aluminous Rich Laterite Depositions through Hyper Spectral Remote Sensing. International Journal of Geosciences, 9, 93-105.

https://doi.org/10.4236/ijg.2018.92006

Received: November 3, 2017

Accepted: February 10, 2018

Published: February 13, 2018

Copyright (c) 2018 by authors and Scientific Research Publishing Inc. This work is licensed under the Creative Commons Attribution International License (CC BY 4.0).

http://creativecommons.org/licenses/by/4.0/

\begin{abstract}
Increased dimensionality of the satellite data proves to be very useful for discriminating features with very close spectral matching. Present study concentrates on the retrieval of reflectance spectra from the level one radiometrically corrected data in Koraput district (Orissa) for the Bauxite ore. In the present study, atmospheric correction model FLAASH has been used to retrieve reflectance from the radiance data. Preprocessing of the dataset has been done before applying atmospheric correction on the dataset. Spectral subsetting of noise prone bands has been successfully done. Local destriping of the affected bands has been done using a $3^{*} 3$ local mean filter. Spectral signatures of samples were derived from the processed data. Spectral signature of each sample and derived features vectors were correlated with the satellite image of the area and distribution of each feature was demarcated. Spatial abundance of each feature was used in preparation of mineral abundance map. Accuracy of the map was assessed using training sets of representative geological units. The mineral abundance mapping using the spectral analysis of the reflectance image involves the endmember collection using the N-Dimensional visualizer tool in ENVI software. Laterite, Bauxite, Iron and silica rich Aluminous laterite soil, Alluvium and Forest were selected as the end members after understanding the geology and analysis of the reflectance image. Various mapping techniques were applied to generate the final classified mineral abundance Map, Linear Spectral Unmixing, Mixture Tune Matched Filtering, Spectral Feature Fitting, Spectral Angle Mapper were the techniques used. Results have revealed the ability of Hyper spectral Remote sensing data for the identification and mapping of Hydrothermal altered products like Bauxite, Aluminous
\end{abstract}


Laterite. This technology can be utilized for targeting minerals in the altered zone.

\section{Keywords}

Hyperspectral Remote Sensing, Aluminous Rich Laterite, Imaging Spectroscopy, Hydro Thermal Altered Ores

\section{Introduction}

One of the most promising and advanced remote sensing technique which is meant solely for mineral exploration is hyperspectral remote sensing also known as imaging spectrometry. Typically, hyperspectral spaceborne imaging spectrometers have been developed to measure the solar reflected upwelling radiance spectrum from $350 \mathrm{~nm}$ to $2560 \mathrm{~nm}$ at 5 to $10 \mathrm{~nm}$ resolution. Reflectance data in each spectral channel are pictorially represented as an image composed of discrete elements-pixels. Hyperspectral imagers collect data in contiguous narrow bands (up to several hundred bands) in the electromagnetic spectrum. They produce vast quantities of data because of the number of bands simultaneously imaged. Hyperspectral data provide unique capabilities to discern physical and chemical properties of Earth surface features which are difficult using current broad-band multi-spectral satellites. High spectral resolution allows identification of materials in the scene, while high spatial resolution locates those materials [1]. Hence, hyperspectral data have enormous potential in target detection, high quality material mapping and identification.

The distribution of the hyperspectral data in $n$-space can be used to estimate the number of spectral endmembers and their pure spectral signatures help to understand the spectral characteristics of different materials. In the present study the typical reflectance spectra of Alumina rich laterite (Bauxite) which can be determined at $2200 \mathrm{~nm}$ was emphasized and employed to identify the new mineral deposits [2].

The present study area, a Precambrian metamorphic terrain is situated in the Eastern Ghats of India [3]. It is located east of Koraput town in the southern part of Orissa having geographic coverage $19^{\circ} 02^{\prime} 29.11^{\prime \prime} \mathrm{N}, 83^{\circ} 04^{\prime} 00.24^{\prime \prime} \mathrm{E}, 19^{\circ} 01^{\prime} 28.28^{\prime \prime} \mathrm{N}$, $83^{\circ} 08^{\prime} 14.50^{\prime \prime} \mathrm{E}, 18^{\circ} 49^{\prime} 56.80^{\prime \prime} \mathrm{N}, 83^{\circ} 01^{\prime} 04.54 " \mathrm{E}, 18^{\circ} 49^{\prime} 19.06^{\prime \prime} \mathrm{N}, 82^{\circ} 05^{\prime} 24.12^{\prime \prime} \mathrm{E}$ as latitude and longitudes (Figure 1). The extent of the area is about $900 \mathrm{sq} \cdot \mathrm{kms}$. The data used in the present study is Hyperion data. Hyperion is having Wavelength range $-400-2500 \mathrm{~nm}$, Spatial Resolution -30 meters, Spectral Resolution -10 $\mathrm{nm}$.

The objectives of the present study are as follows.

1) Laboratory spectra generation of different rock samples from the representative horizons using ASD spectroradiometer.

2) Establish the occurrence of mineral deposits of Bauxite from known to unknown areas. 


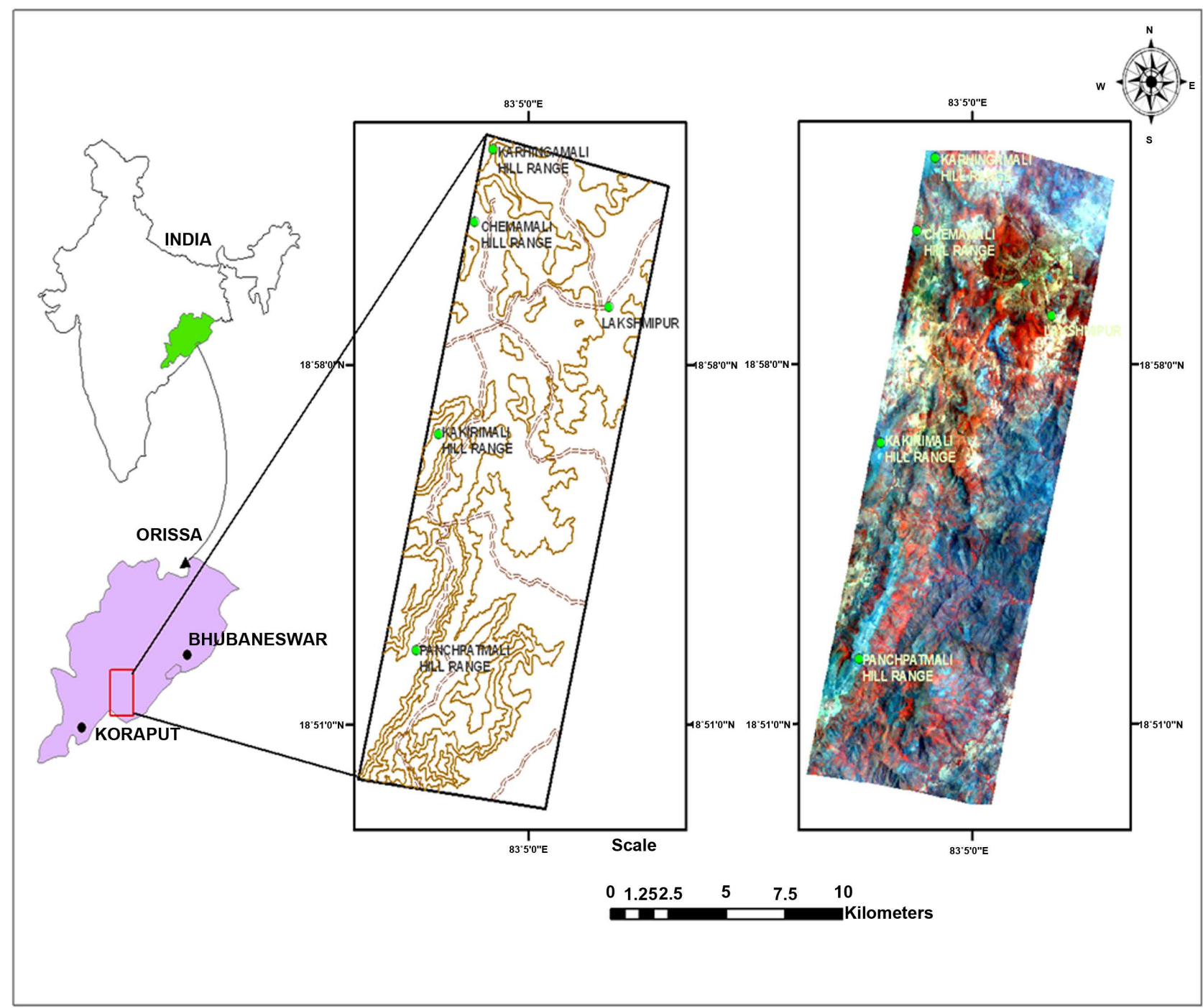

Figure 1. Location of the study area.

\section{Materials and Methods}

In the present study Hyperion data and SOI topo sheet $65 \mathrm{~N} 1$ and 65 M4 were used to map the aluminous rich Laterite/Bauxite deposits in the parts of Koraput district of Orissa. Hyperion sensor is a hyperspectral imager on-board of EO-1 satellite. There are 220 spectral bands ranging from $400-2500 \mathrm{~nm}$. The spatial resolution is 30 meter per pixel and swath width is $7.7 \mathrm{~km}$. Each scene covers either $42 \mathrm{~km}$, or $185 \mathrm{~km}$. The product is distributed by USGS, and the level one product, which is only radiometrically corrected and the image is processed using softwares ENVI, ERDAS and ARC MAP.

\section{Methodology}

\subsection{Preprocessing of Hyperspectral Data}

The Hyperion dataset has to be corrected for abnormal pixels, striping and smiling prior to the atmospheric correction. Pre-processing of hyperspectral 
images is required not only for removing sensor errors during acquisition but also for display, band selection (to reduce the data dimensionality) and to reduce computational complexity.

\subsection{Spectral Subsetting}

The Hyperion sensor covers the visible and near infra-red (VNIR, or $400 \mathrm{~nm}$ to $1000 \mathrm{~nm}$ ) and shortwave infra-red (SWIR, $900 \mathrm{~nm}$ to $2500 \mathrm{~nm}$ ) ranges. The instrument has a single telescope but two spectrometers-one for the VNIR and the other for the SWIR data. The VNIR spectrometer has 70 bands and the SWIR 172 bands providing 242 potential bands which are normally about $10 \mathrm{~nm}$ apart in each spectrometer and have spectral response functions with approximately $11 \mathrm{~nm}$ full-width at half maximum (FWHM). If every band were operating, the spectral range covered would be from $356 \mathrm{~nm}$ to $2577 \mathrm{~nm}$ with a common area of overlap between the spectrometers between $852 \mathrm{~nm}$ and 1058 $\mathrm{nm}$. In practice a number of the bands were not illuminated and others correspond to areas of low sensitivity of the spectrometer material so that the 242 a subset of 198 bands spectrally sub-setted from the Hyperion data set.

VNIR Range: Bands 8 - 57 (436 - $926 \mathrm{~nm})$

SWIR Range: Bands 77 - 224 (892 - 2406 nm)

These results in 198 useable channels or bands with 196 unique wavebands

Hence the redefined spectral ranges of the Hyperion image set is as follows.

VNIR Range: Bands 8 - 57 (436 - 926nm)

SWIR Range: Bands 79 - 224 (933 - $2406 \mathrm{~nm}$ )

The basic 196 unique data channels that was further used for analysis.

\subsection{Destriping of VNIR and SWIR Region}

A vertical stripe is said to occur where the statistics indicate that the image information is likely to be valid, i.e. pixel is not bad but have significantly modified gain and offset. In a pushbroom sensor, a poorly calibrated detector in either VNIR or SWIR array leaves high frequency errors ("vertical stripes") on the image bands.

\subsection{Identification of Bad Columns}

In the present study the bad columns were identified visually to avoid enforcing severe change in the spectra. A total of 36 bad columns were identified in dataset. SWIR bands were found devoid of visible stripes.

\subsection{Balancing for Bad Columns}

Bad columns were identified visually and bad column removal filter was used to target the bad columns in each band. The bad columns were replaced by the $3 \times$ 3 neighbourhood mean, without taking into account the bad column value.

\subsection{Atmospheric Correction}

ENVI's FLAASH (Fast line of sight Atmosphere Analysis of Spectral Hyper 
cubes) was used for the retrieval of reflectance from radiance. FLAASH starts from a standard equation for spectral radiance at a sensor pixel, $L$, that applies to the solar wavelength range (thermal emission is neglected) and flat, Lambertian materials or their equivalents. The equation is as follows:

$$
L=\left(A \rho / 1-\rho_{e} S\right)+\left(B \rho_{e} / 1-\rho_{e} S\right)+L_{a}
$$

After the water retrieval is performed, Equation (1) is solved for the pixel surface reflectance in all of the sensor channels. The solution method involves computing a spatially averaged radiance image is estimated using the approximate equation

$$
L_{e}=(A+B) \rho_{e} /\left(1-\rho_{e} S\right)+L_{a}
$$

Once the atmospheric correction model is run, the reflectance is retrieved from the radiance.

\subsection{Field Spectra Collection}

The validation of the reflectance spectra has been done with the analytical spectral device Fieldspec to generate the laboratory spectra of the rock samples that have collected from the field. The spectral collection of the rock samples were conducted almost at the same time of the sensor image capturing time. This was done to regenerate the same illumination conditions that persisted at the time of the image capture IN order to make measurements of surface reflectance of geological samples.

\subsection{Spectral Data Collection, Creation of ASD and Image Spectral Library}

To compare the ground-measured spectra collected from ASD with that of atmospherically corrected image spectra, the ASD spectra were re-sampled to the Hyperion FWHM and bandwidth. A spectral library of re-sampled ASD spectra was created. The spectra from the ASD library were used as standard to compare image reflectance spectra extracted using FLAASH. The ground control points collected during the ground truth investigation were used to locate the exact pixel in the image which corresponds to the respective sample location. The image spectra for all the major sampling locations were generated similarly and saved in spectral library.

\section{Methodology for Mineral Mapping Using Spectral Analysis}

\subsection{Minimum Noise Fraction}

The minimum noise fraction (MNF) transformation is used to determine the inherent dimensionality of image data, Minimum Noise Fraction images were created for the 196 unique bands of Hyperion data. Around 10 MNF components contained the maximum information. The remaining bands contain maximum noise. Hence the first 10 bands were used for further processing and for selecting pure pixels in the image [4]. 


\subsection{Pixel Purity Index}

In the present study, number of iterations with different threshold limit was carried out interactively to isolate the position of most pure pixels in the image [5]. A threshold of two was fixed for the identification of pure pixels in the image which can be explained as, all the pixels having $2 \mathrm{DN}$ values (maximum limit) greater than the extreme pixel is considered as being pure. Different sets of iterations 50,100, 500 and 1000 were carried out on this dataset with keeping the threshold at 2. It was observed that more the number of iterations more the number of extreme pixels found with more variability in the dataset.

\subsection{Process of Selection of Image End Members, Mineral Mapping Techniques}

In the study area, all the relevant topographic features are clustered in the $\mathrm{N}$-Dimensional visualizer and demarcated as separate region of interests and saved. These ROI's were used for the further mapping using various techniques. The endmembers clustered in the study area are as follows. 1) Al rich Laterite/Bauxite 2) Khondalite 3) Weathered soil with agriculture 4) Weathered soil 5) Vegetation

\subsection{Linear Spectral Unmixing}

Linear Spectral Unmixing is a means of determining the relative abundances of materials depicted in multispectral imagery based on the materials spectral characteristics. The reflectance at each pixel of the image is assumed to be a linear combination of the reflectance of each material (or endmember) present within the pixel.

A unit-sum constraint in the linear Mixing algorithm was applied in this study where the score varies between zero and one. This was implemented to allow user-defined weighting of a sum-to-unity constraint on the abundance fractions. It also permits proper unmixing of MNF-transform data, with zero-mean bands. The weight factor, a default value of one is used for the extra constraint equation. This weighted unit-sum constraint is then added to the system of simultaneous equations in the unmixing inversion process [6].

\subsection{Mixture Tuned Matched Filtering}

Mixture tuned matched filtering (MTMF) performs a partial unmixing-finding the abundances of user defined endmembers.

Mixture Tuned Matched Filtering technique combines the best part of the linear spectral unmixing model and the statistical matched filter model while avoiding the drawbacks of each model. From matched filtering it inherits the advantage of its ability to map a single known target without knowing the other background endmember signatures, unlike traditional spectral mixing models. From spectral mixture modeling it inherits the leverage arising from the mixed pixel model, the constraint on feasibility including the unit sum and positive re- 
quirements unlike the Matched Filter which does not employ these fundamental facts [7]. Hence this method can out perform either method in case of subtle, sub-pixel occurrences.

\section{Results and Discussions}

In the present work a customized tool was used to compensate for the striping by visually identifying bad columns and a filter was developed to balancing for the bad columns. Using the cumulative mean, variance, minimum and maximum of each pixel in a column the stripes are identified.

\subsection{Forward MNF Transformation}

MNF transformation was applied on the Hyperion data. Several trials of Minimum Noise Fraction transformation have been run to obtain the optimum results. The first 10 eigenvectors (Figure 2) were chosen for both the datasets and the rest of them were more noise prone hence discarded from further spectral analysis. The FCC using the first 3 bands of MNF Transformation [8].

\subsection{Pixel Purity Index Results}

The pixel purity index image was derived from the MNF image (Figure 4). The number of iterations was chosen as 10000 with 250 iterations per block, given a threshold of 2. The threshold were changed and tested on various MNF images of the study area. It was found that the threshold value of 2 has given the best

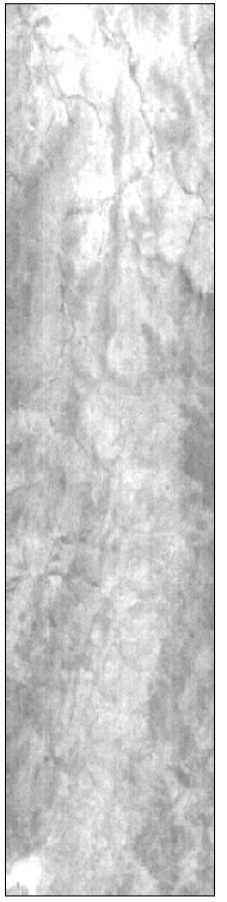

Eigen vector-1

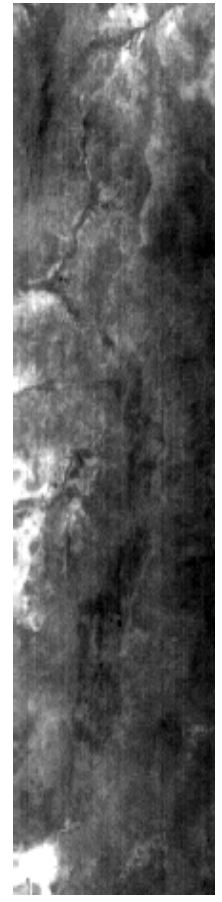

Eigen vector-2

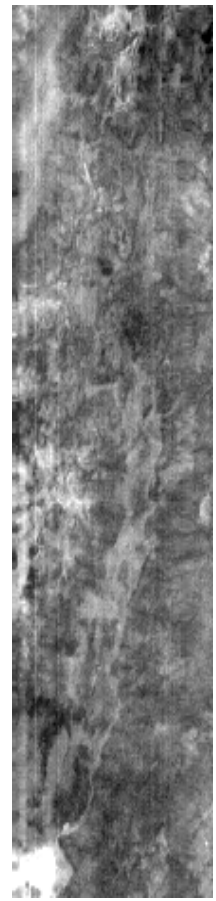

Eigen vector-3

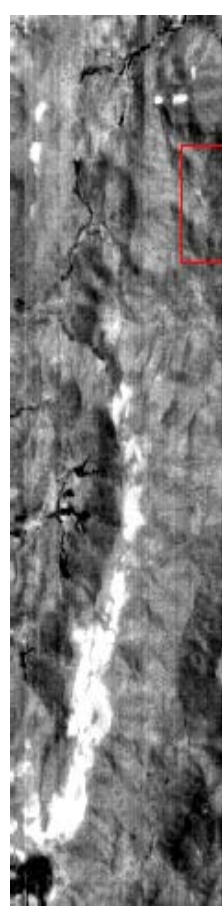

Eigen vector-4

Figure 2. Eigen vectors derived from the Hyper spectral data. 
results and hence been chosen for further selection of the region of interests (ROIs).

\subsection{Endmembers Selection}

The endmember needs to be selected for the abundance mapping using various mapping methods such as Linear Spectral Unmixing (LSU), Mixed Tuned Matched Filtering (MTMF) and Matched Filtering etc. The various endmembers are chosen with respect to their relevance in the study area and the geologically relevant features are chosen as endmembers (Figure 3).

\section{Results of Various Mapping Techniques}

\subsection{Results of Linear Spectral Unmixing}

Linear spectral unmixing has been performed using the final endmembers of the study area. It is obtained by giving endmember region of interest as the reference spectra and their abundance in the image are given in the resultant final Linear spectral unmixing image.

The linear spectral unmixing result of the study area clearly demarcates the Bauxite ore. This is basically due to the mineral composition of the mineral. It has the characteristic absorption depth at $2200 \mathrm{~nm}$ that enables these minerals to be distinguished in the image, the abundance has also been successfully mapped using the linear spectral unmixing model.

\subsection{Results of Mixture Tuned Matched Filtering}

Image endmembers are derived from the hyperion satellite imagery using the interactive analysis technique of ENVI. All the final image endmembers mostly

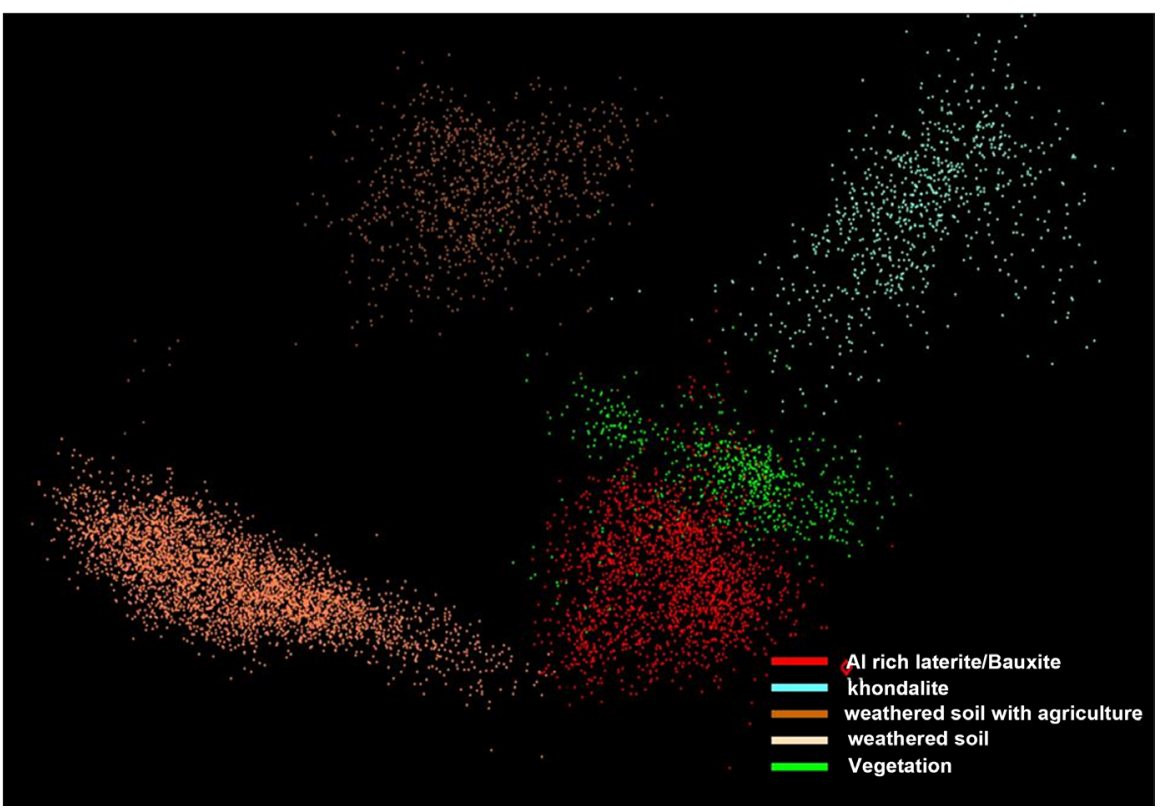

Figure 3. Isolated Endmembers of selected classes in n-Dimension Visualiser \& Isolation of Pure pixels from the MNF image. Red-Al rich laterite/Bauxite; Aquamarine-Khondalite; Sienna-Weathered soil with agriculture; Coral—Weathered soil; Sea green-Vegetation. 
describing the image were considered for creating a set of score and infeasibility image.

The interpretation of mixture tuned matched filtering mapping method involves the integration of close analysis of both the score and infeasibility images of the individual endmembers. The $\mathrm{Al}$ rich laterite/Bauxite and Vegetation endmember's score as well as infeasibility image are given in (Figure 4). The score images of Bauxite exhibits their abundance in the area with high pixel values and they can be considered only valid if the same area has low pixel values in the infeasibility image (Figure 5).

\subsection{Supervised Classification and Mineral Abundance Map}

Maximum Likelihood Classifier was applied to the MNF transformed components, using the ROI's of selected endmembers. In order to compare the results with those from the Maximum likelihood, the classification thresholds are adjusted to 2 . The ground truth makes it easy to make absolute performance comparisons. Classified Image was examined for its validity by using the error matrix of ground truth ROI's which were collected during the Field Visit of the Study area and the sample spectra that were collected.

\section{Results}

For study area, linear spectral unmixing MTMF were used to map the endmembers. The five endmembers used for the study area are Laterite/Bauxite, khondalite, weathered soil with agriculture, weathered soil and Vegetation. The linear spectral unmixing method successfully mapped the weathered soil with agriculture and weathered soil but showed intermixing between bauxite/laterite and khondalite abundance image. The MTMF method was adopted for the study

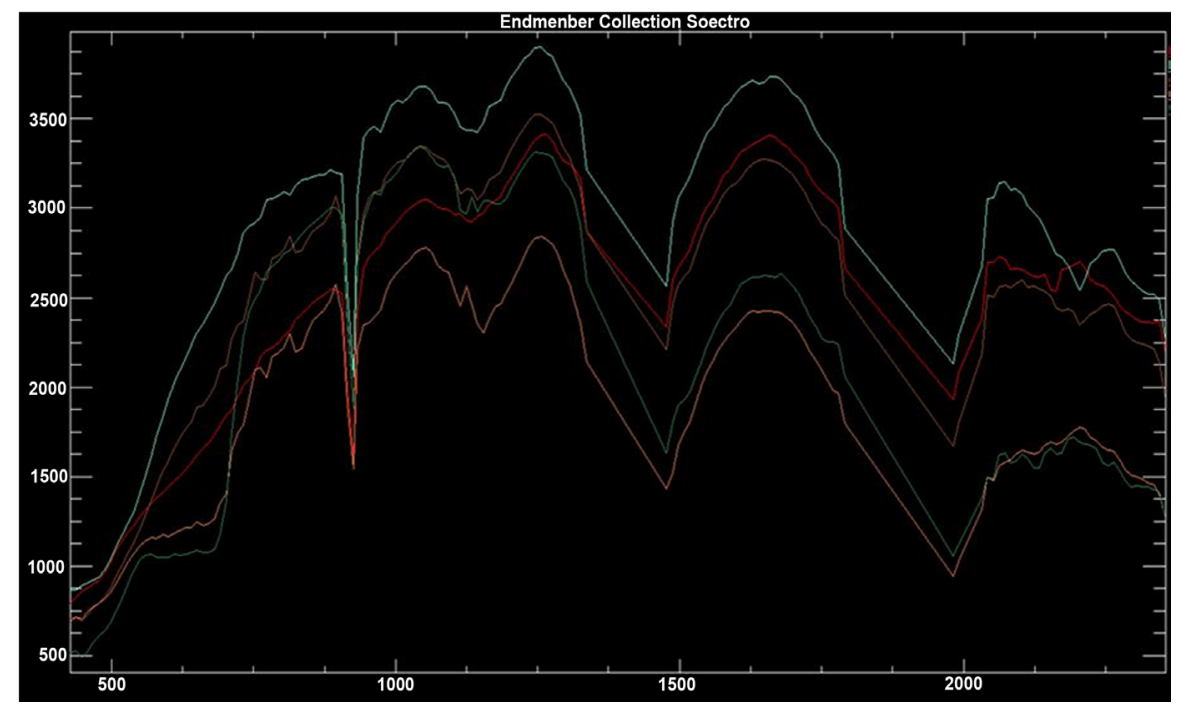

Figure 4. Spectra generated from the selected classes. Red-Al rich laterite/Bauxite; Aquamarine-Khondalite; Sienna-Weathered soil with agriculture; Coral-Weathered soil; Sea green-Vegetation. 


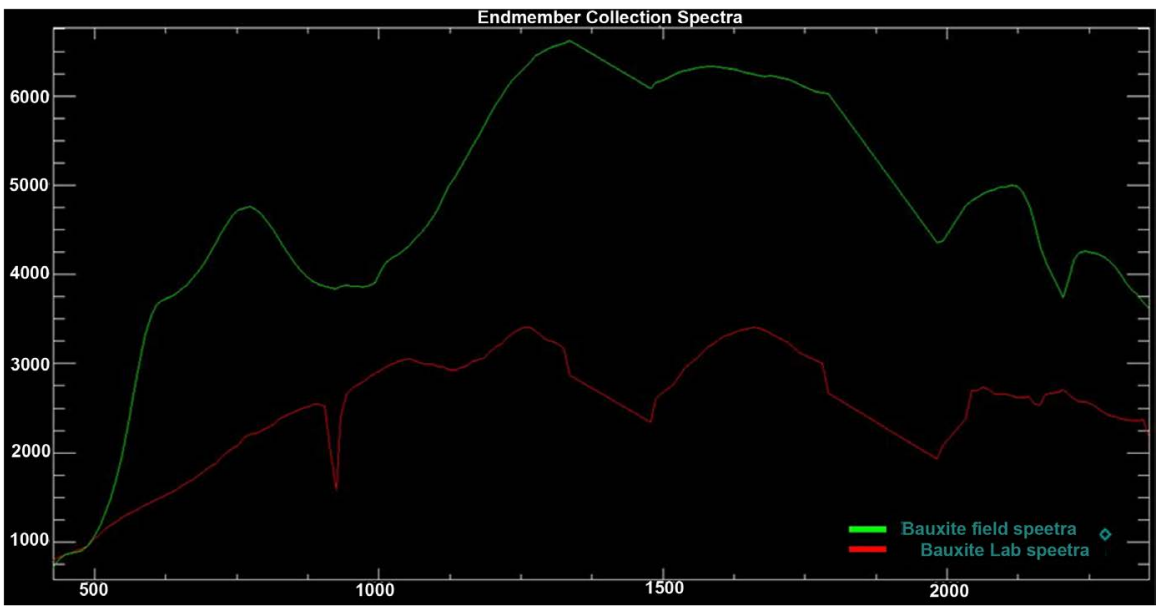

Figure 5. Comparison of Lab spectra and field spectra collected for Bauxite.

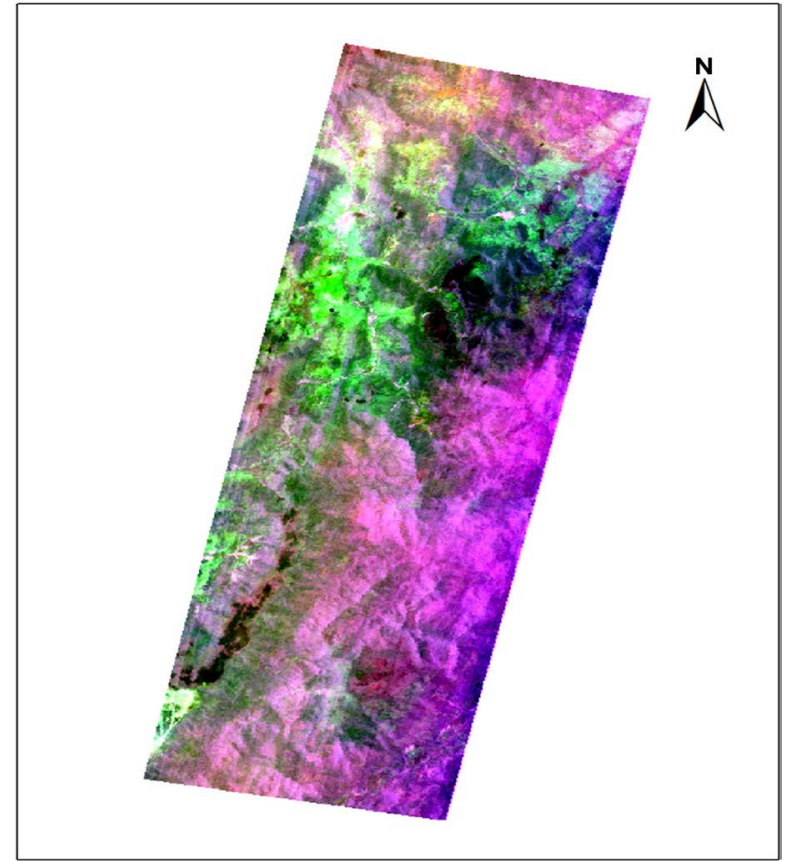

Figure 6. Linear spectral unmixing FCC image.

area primarily to differentiate between the bauxite/laterite and khondalite, which were intermixed in the Linear spectral unmixing result. The MTMF successfully conducted the abundance mapping for bauxite/laterite and khondalite (Figure 6). The final interpretation of the MTMF results needs to be done after integrating the score image results to that of the infeasibility image for all the endmembers. Mineral abundance Map of $\mathrm{Al}$ rich Laterite/Bauxite was prepared with identified new mineral deposits in unknown areas (Figure 7). Identified deposits were (Figure 8).

- KARHINGA MALI HILL $\left(83^{\circ} 4^{\prime} 10^{\prime \prime} \mathrm{E}, 19^{\circ} 2^{\prime} 9^{\prime \prime N}\right)$

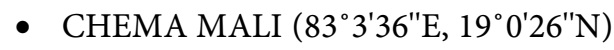

- KAKIRIMALI $\left(83^{\circ} 2^{\prime} 55^{\prime \prime} \mathrm{E}, 18^{\circ} 56^{\prime} 52^{\prime \prime} \mathrm{N}\right)$ 


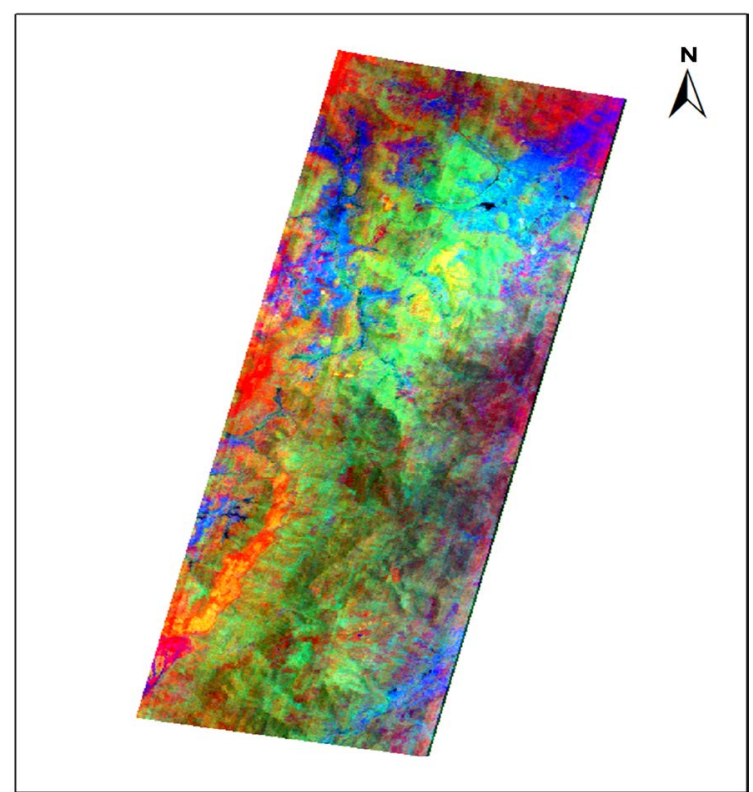

Figure 7. MTMF image FCC of Al rich laterite/Bauxite, Khondalite and weathered soil Score Images.

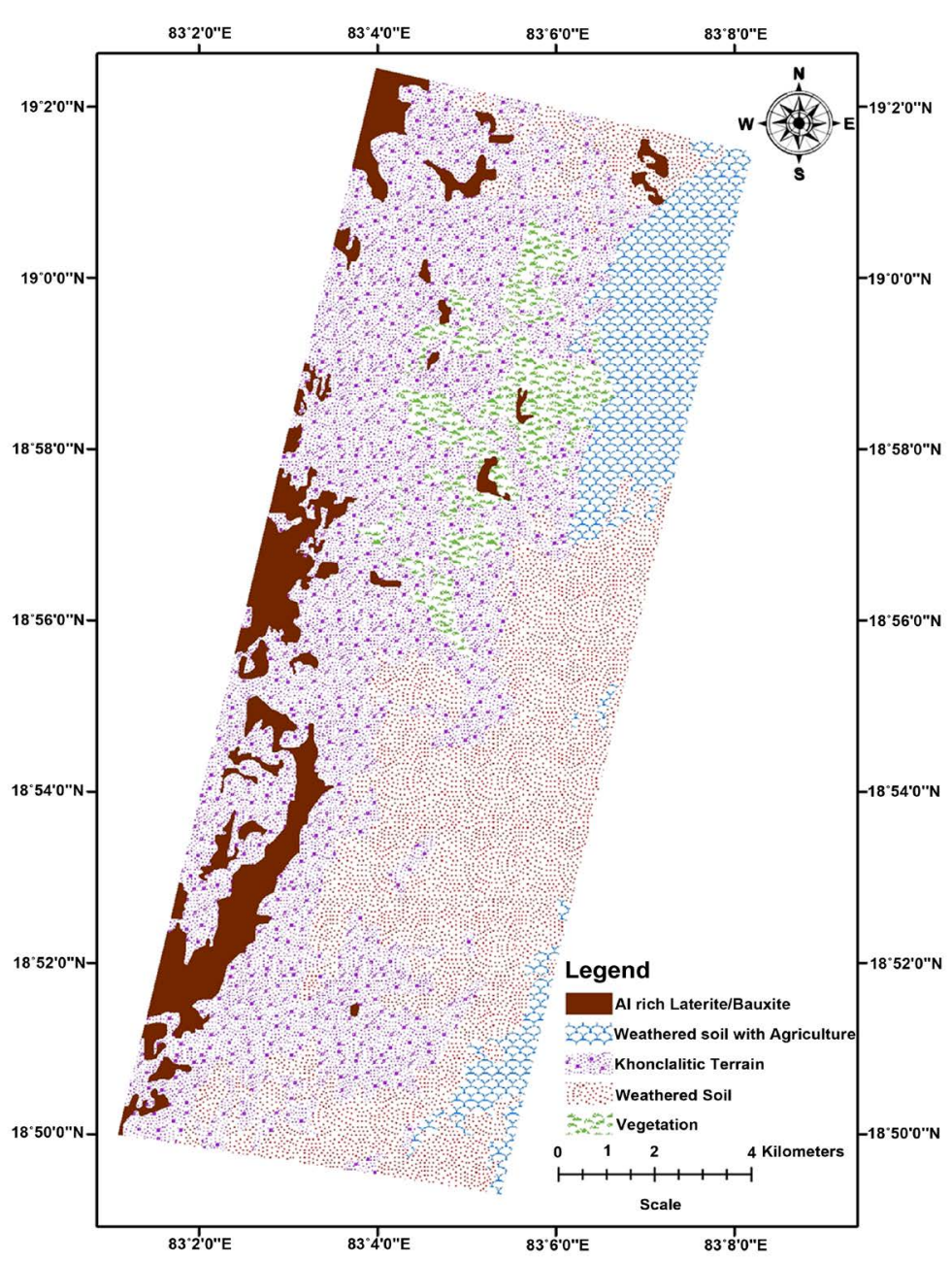

Figure 8. Land cover Map. 


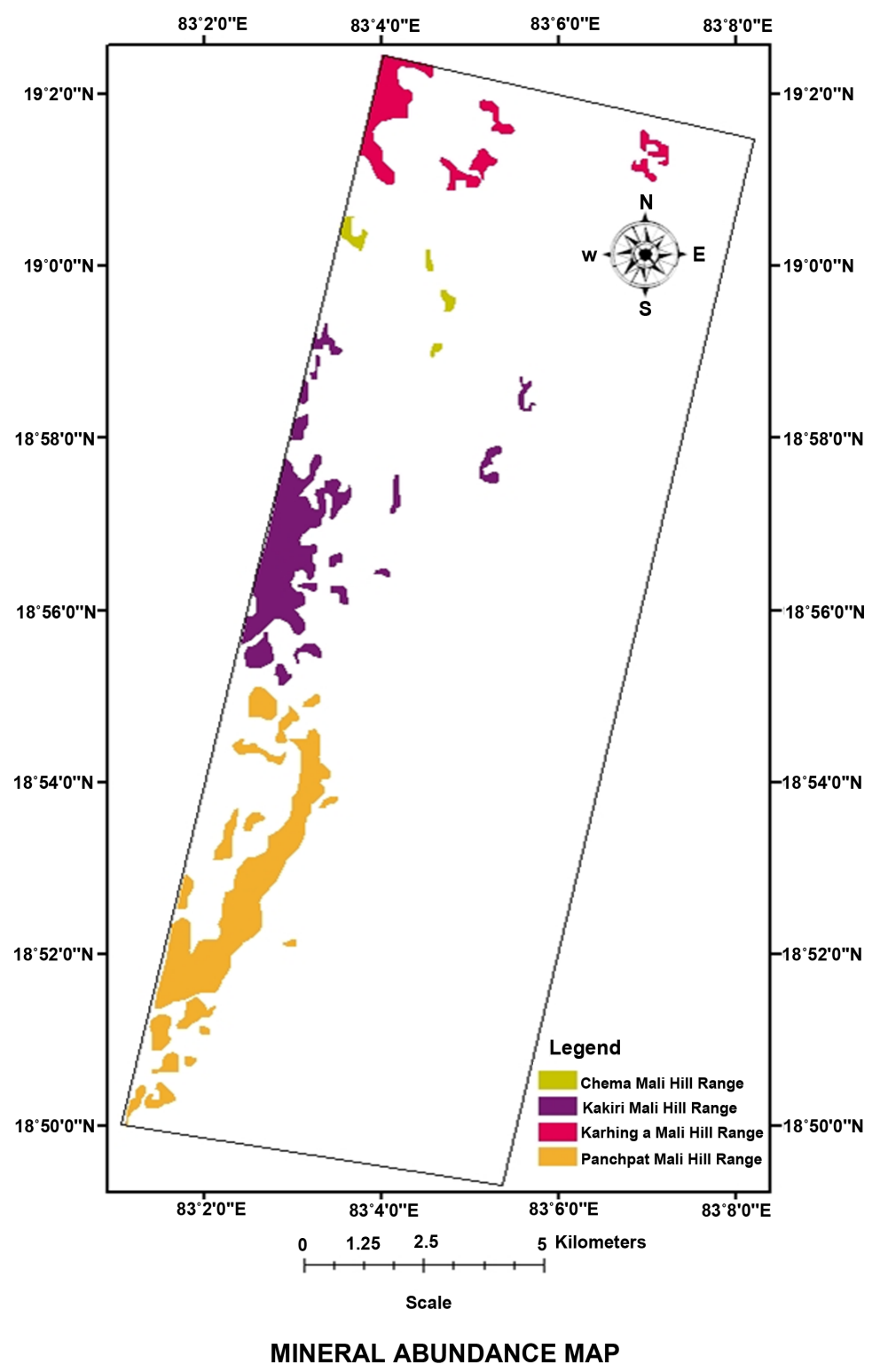

Figure 9. Map showing Alumina rich Laterite occurrence in the study area.

\section{Conclusion}

In the present study the typical reflectance spectra of Alumina rich Laterite (Bauxite) at $2200 \mathrm{~nm}$ was emphasized and employed to identify the new mineral deposits. Results have revealed the ability of hyperspectral remote sensing data for the identification and mapping of weathered altered products like $\mathrm{Al}$ rich Laterite (Bauxite). Mapping techniques that were employed in this study were Linear Spectral Unmixing, Mixture Tune Matched Filtering. A single mapping technique has not given all the endmember classified result. For the study area, linear spectral unmixing as well as Mixture Tune Matched Filtering has given good results. Hence it can be concluded that an integrated approach of several mapping techniques will lead to the successful mapping of the endmembers (Figure 9). 


\section{Acknowledgements}

I am grateful to Dr. George Joseph, Director, CSSTEAP, Dr. Yogesh Kant, Dr. Saha Dr. S. P. Aggarwal, and Prof. G. Jaisankar for extending their full support and providing the guidance throughout the study.

\section{References}

[1] Lillesand, T.M. and Kiefer, R.W. (1999) Remote Sensing and Image Interpretation. John Wiley \& Sons, Inc., New York, 9-597.

[2] Dash, B. and Das, J.K. (1969) A Structural Study of Eastern Ghat Tectonic around Tigira, Orissa. Prakruti Utkal University Journal Science, 45, 173-176.

[3] Rao, M.G. and Raman, P.K. (1979) The East Coast Bauxite Deposits of India. Bulletin. Geological Survey of India. Series A, No.46, 24.

[4] Hunt, G.R., Salisbury, J.W. and Lehnoff, C.J. (1971) Visible and near Infrared Spectra of Minerals and Rocks: 111. Oxides and Oxyhydroxides. Modern Geology, 2, 195-205.

[5] Boardman, J.W., Kruse, F.A. and Green, R.O. (1995) Mapping Target Signatures via Partial Unmixing of AVIRIS Data. Summaries, Fifth JPL Airborn Earth Science Workshop, 23-26 January 1995, JPL Publication 95-1, 1, 23-26.

[6] Jupp, D.L.B., Datt, B., Lovell, J., Campbell, S. and King, E. (2004) Backgroung Notes for Hyperion Data User Workshop. CSIRO Office of Space Science and Applications, Earth Observation Centre, Canberra.

[7] Boardman, J.W. and Kruse, F.A. (1994) Automated Spectral Analysis: A Geologic Example Using AVIRIS Data, North Grapevine Mountains, Nevada. Proceedings, Tenth Thematic Conference on Geologic Remote Sensing, Environmental Research Institute of Michigan, Ann Arbor, MI, 407-418.

[8] Green, A.A. and Craig, M.D. (1985) Analysis of Aircraft Spectrometer Data with Logarithmic Residuals (abs). Proceedings, AIS Work Shop, 8-10 April 1985, Jet Propulsion Laboratory, Pasadena, 85-41. 